\title{
Living wills, powers of attorney and medical practice
}

\author{
Raanan Gillon Imperial College and King's College, London University
}

As a British working party commends the principles upon which American 'living will' statutes are based (1), an American medical ethicist argues in this issue that those very values are in many cases threatened by the legislation itself (2). For despite being born of a widespread desire to enhance patients' autonomous choices concerning their medical care after they have ceased to be able to make such choices, American 'living will' laws often in practice impair that choice, especially by imposing two types of restriction on people's common-law rights to refuse medical treatment, argues Professor Lawrence Heintz.

The two 'fatal flaws that have found their way into most legislation in this area of health care' are first that patients must be certified 'as qualified' in order to have their living wills respected and second that in many statutes only terminally ill patients can qualify for such 'certification'. Both restrictions, argues Professor Heintz, tend in practice to mean that the prior competent wishes of patients who are not certified 'as qualified' are even less influential in their medical care once they have become incompetent than was the case before the advent of 'liberalising' living will legislation. Such problems are particularly likely to arise where the statutes do not explicitly preserve existing common law rights, notably to refuse medical treatment.

Questions about the practical effects of living will statutes are of considerable importance to countries where none exist but where desires for such legislation are beginning to be expressed. The British multidisciplinary working party convened by Age Concern and the Centre for Medical Law and Ethics of King's College, London University concludes, in its recently completed report, that some improvements in the status quo are required, but is suitably cautious about recommending what changes would be optimal. Instead the report analyses the ethical, legal and practical issues, demonstrating in its impressive awareness of the medical, nursing and social, as well as the moral and legal aspects of the matter the great value of multidisciplinary inquiry of this kind(1).

The report begins by pointing to the ethical and legal uncertainties about provision, withholding and withdrawal of treatments where patients are incompetent, especially when those treatments can be expected to prolong life. On the one hand may potentially harmful treatments be given without consent, on the other may life-prolonging treatments be withheld or withdrawn without consent?

The working party rejects the response of the British Medical Association (BMA) that no changes are necessary since it is already permissible both in medical ethics and English law for doctors to make such decisions and for patients to inform their doctors, orally or in writing, about how they would wish to be treated or not treated. The working party responds that (a) not many people know that such provisions exist and (b) that the current legal uncertainties allow doctors' responses to such requests too much latitude, even arbitrariness, with only some doctors being prepared to commit themselves to respecting their patients' wishes, others insisting on doing what in their opinion would be best, regardless of their patients' earlier expressed wishes.

The working party believes that just as doctors should respect the autonomy of their competent patients and not impose treatments against their will not even life-prolonging treatments - so they should respect the previously manifested autonomous wishes of their now incompetent patients, and ways of achieving that objective must be developed. Such a requirement becomes ever more important as medical technology exponentially increases the power of doctors to maintain life, at least in some sense of the term, far beyond their 'ability to assure the quality of that life'.

The working party focuses on three groups of conditions in contemplation of which many people might wish to provide advance directives concerning their medical care. These are terminal illness, in which medical care cannot avert death for more than a fairly short time; serious and permanent illness or disablement in people who require treatment to stay alive but who, given such treatment can stay alive for long periods (such states would include permanent vegetative states such as that of Karen Quinlan); and severe and irreversible dementia in which there is no particular threat to life but contemplating which many competent people would (a) wish to try to prevent others from doing anything to keep them alive if natural processes would lead to their death and (b) wish their doctors to employ whatever medical measures 
were available to prevent antisocial or even merely undignified behaviour.

Starting from what its legal advisers believe English law to permit and require of doctors in their dealings with competent patients the working party offers an analysis of existing English law in relation to incompetent patients. Though it states this to be uncertain it agrees with Skegg that in essence English law would require doctors to respect a patient's clear wishes previously expressed: 'if the patient has foreseen the circumstances which have since arisen and there is no reason to believe that he would have changed his mind if still capable of doing so, the doctor should only be justified in proceeding to the same extent as he could if the patient were still capable of consenting'. As with the judgement in the American case of Conroy, 'if known, the patient's wishes would be determinative' in refusal of treatment, including artificial feeding and hydration.

In cases where the patient's clear prior competent wishes were unknown the working party believes, again consistent with the Conroy judgement, that English law and ethical analysis would support a version of the ordinary/extraordinary means principle, though shorn of its misleading name: 'the distinction between unduly burdensome and beneficial treatments is morally determinative and should also be legally conclusive ... the benefit/burden balance is, and should be, part of English law'; and that assessment 'should be seen from the patient's point of view' so far as is possible.

Acknowledging however that English law in these matters is unclear and its interpretation of it somewhat speculative, the working party considers various options for improving matters, having rejected the BMA'S preference for leaving matters as they are. In particular it assesses the advantages and disadvantages of the three American developments, durable powers of attorney for health care decisions, living wills, and combinations of the two, introduced either by statute (with the statutory provisions being either mandatory or merely advisory for the doctors concerned) or informally via medical and public educational campaigns and by widespread provision of proforma documents.

While pointing out that 'the issues are sensitive and complex' and that a comprehensive set of recommendations would 'perhaps be precipitate', the tenor of the report's final chapter is to recommend either the introduction of living wills on an informal basis or the introduction by statute of a durable power of attorney for health care decisions. If the latter were introduced the report recommends that proxies should be obliged to make decisions on the basis of 'substituted judgement' rather than the patient's 'best interests', and preferably in the context of some form of co-existing living will. Thus the proxy should act as 'a sympathetic interpreter of the patient's wishes' rather than either 'an objective judge of what would be in the patient's best interests' or 'an ombudsman arbitrating between the views of all the interested parties'.

One puzzling aspect of the working party's analysis is its insistence that the durable power of attorney provision could only be introduced by statute. The non-statutory advice of a proxy, competently chosen by a presently incompetent patient, about what he or she believes the patient's wishes would be is surely already valuable to a doctor in deciding whether or not to provide or continue a particular treatment. Informal measures that would provide reliable advice from patients to doctors about who those proxies should be ('proxy' seems to have less legalistic a ring than 'attorney') are surely as easily developed as are informal living wills, and indeed the two can be combined in a single document.

Nor need such informal measures be limited to signed and witnessed living wills which also name a proxy. For example perhaps patients could be routinely offered the opportunity to give the relevant information on entering hospital or on signing up with a general practitioner.

There are undoubtedly moral and legal uncertainties in medical practice relating to the provision, withholding or withdrawal of any medical treatment, especially life-prolonging treatments, in the cases of incompetent patients, including those categories considered by the King's and Age Concern Working Party. As the working party makes clear, both types of problem would be ameliorated if patients' prior wishes, competently expressed, were available to, and respected by, the doctors treating them. To allay doubts that such wishes would be respected perhaps the medical organisations - General Medical Council, Royal Colleges, BMA - should make clear that doctors would and should welcome such information and do their best to act upon it.

It seems generally preferable to avoid legislation in the delicate area of personal medical care if the legitimate objectives of patients, health care workers and society can be achieved without it. In the case of advance directives there need be no clash of such objectives. However, the health care professions and especially medicine would surely do well to heed the concerns expressed in the King's and Age Concern Report and take active steps to respond to them positively, encouraging innovations that can improve matters within the framework of existing law and existing best practice. Legislation remains a possibility if public concern is not allayed, in which case its problems, discussed both in the report and by Professor Heintz, will need very careful consideration.

\section{References}

(1) Living Wills Report: in press. See page 106 of this issue for a summary.

(2) Heintz L L. Legislative hazard: keeping patients living, against their wills. Fournal of medical ethics 1988; 14: 8286. 